\title{
Effectiveness of exercise therapy versus occlusal splint therapy for the treatment of painful temporomandibular disorders: a systematic review and meta-analysis
}

\author{
Ling Zhang ${ }^{1}$, Lili $\mathrm{Xu}^{1}$, Dandong $\mathrm{Wu}^{2}$, Chunhua Yu ${ }^{3}$, Shuai Fan ${ }^{1}$, Bin Cai ${ }^{1}$ \\ ${ }^{1}$ Department of Rehabilitation, Shanghai Ninth People's Hospital, Shanghai Jiao Tong University, School of Medicine, Shanghai, China; \\ ${ }^{2}$ Department of Rehabilitation, The Second Affiliated Hospital of Chongqing Medical University, Chongqing, China; ${ }^{3}$ Department of \\ Prosthodontics, Shanghai Ninth People's Hospital, Shanghai Jiao Tong University School of Medicine, Shanghai, China \\ Contributions: (I) Conception and design: B Cai; (II) Administrative support: D Wu, L Xu; (III) Provision of study materials or patients: L Zhang, \\ D Wu, S Fan; (IV) Collection and assembly of data: L Zhang, L Xu, D Wu; (V) Data analysis and interpretation: C Yu, L Zhang; (VI) Manuscript \\ writing: All authors; (VII) Final approval of manuscript: All authors. \\ Correspondence to: Bin Cai. Department of Rehabilitation, Shanghai Ninth People's Hospital, Shanghai Jiao Tong University School of Medicine, 639 \\ Zhizaoju Road, Huangpu District, Shanghai 200011, China. Email: shrehab@163.com.
}

Background: This systematic review of the literature was to compare the effects of exercise therapy and
occlusal splint therapy on pain and mobility in individuals with painful temporomandibular disorders (TMD).
Methods: PubMed, Embase and the Cochrane Central Register of Controlled Trials were searched
for English publications from database root to March 1, 2020. Search terms were [("temporomandibular
joint disorders" or "temporomandibular disorders" or "craniomandibular disorders" or "orofacial pain" or
"myofascial pain" or "myofascial pain" or "facial pain") AND (exercise or "physical therapy modalities" or
physiotherapy or "exercise therapy") AND ("splints" or "occlusal splints" or "stabilization splint" or "occlusal
appliance" or "occlusal splint therapy")]. We included randomized controlled trials that evaluated the effects
of therapeutic exercise therapy and occlusal splint therapy, and were published in English. Trial quality was
assessed with the Physiotherapy Evidence Database scale. Results: Six studies were included (498 patients: 251 occlusal splint therapy, 247 therapeutic exercise). The results revealed that exercise therapy was not superior to occlusal splint therapy for pain reduction in patients with painful TMD ( $\mathrm{P}=0.08$; weighted standardized mean difference -0.29 ; $95 \%$ CI, -0.62 to 0.04). The effectiveness of occlusal splint therapy and exercise therapy was found to be equivalent in the maximum mouth-opening range $(\mathrm{P}=0.51$; weighted standardized mean difference $0.12 ; 95 \% \mathrm{CI},-0.24$ to 0.48), right laterotrusion ( $\mathrm{P}=0.99$; weighted standardized mean difference $-0.00 ; 95 \% \mathrm{CI},-0.31$ to 0.31$)$, left laterotrusion ( $\mathrm{P}=0.32$; weighted standardized mean difference $0.16 ; 95 \% \mathrm{CI},-0.16$ to 0.48$)$, and protrusion $(\mathrm{P}=0.77$; weighted standardized mean difference 0.06 ; $95 \% \mathrm{CI},-0.32$ to 0.43 ) for painful TMD patients.

Conclusions: Given the limitations of the study, the small number of studies included in the sub-analysis for pain relief and the maximum mouth-opening range, and the small overall standardized mean difference for pain relief and mandibular movement observed, no high-quality evidence was found to distinguish the clinical effectiveness between occlusal splint therapy and exercise therapy for painful TMD patients. It appears that more randomized controlled trials comparing the effects of exercise therapy and occlusal splint therapy need to be implemented. Keywords: Temporomandibular disorders (TMD); physiotherapy; occlusal splint therapy; systematic review;
meta-analysis

Submitted Feb 24, 2021. Accepted for publication Apr 20, 2021.

doi: $10.21037 /$ apm-21-451

View this article at: http://dx.doi.org/10.21037/apm-21-451 


\section{Introduction}

Temporomandibular disorders (TMD) are common chronic musculoskeletal pain conditions among orofacial pain, consisting of a group of conditions associated with pain and dysfunction of the temporomandibular joint (TMJ) and masticatory muscles (1). The main signs and symptoms are deviations or limitations during mouth opening, and pain in the TMJ, the masticatory muscles region (1). Pain is the most common reason patients seek TMD treatment, affecting approximately $10 \%$ of adults (2). Mandibular dysfunction such as limited mandibular movement may affect daily activities, resulting in lower quality of life, and therefore, the management of these TMD signs and symptoms is a major public health problem (3). Because the accurate etiology of TMD is unknown, conservative modalities are the preferred first-line treatment, and include counseling, medication, manual therapy, therapeutic exercise, and occlusal splint therapy among others (1). Many studies have identified the effectiveness of exercise therapy and occlusal splint therapy to relieve pain and increase mandibular movement for painful TMD $(1,4-6)$.

Occlusal splint treatment is generally considered to be a basic treatment for TMD $(5,7)$. It could promote correction of the vertical dimension, maxillo-mandibular realignment, TMJ repositioning and cognitive awareness (7-9). Although various different splints are currently available, the most commonly used are stabilization splints (9) and anterior repositioning splints (8). Scientific evidence indicates that stabilization splints reduce pain in patients with TMD in the short term, and the Michigan type can even be used to reduce moderate pain (9). There is less evidence for anterior repositioning splints compared with stabilization splints (8). Anterior repositioning splints are recommended for disc displacements to aid the disc to return to the original position (8). However, the anterior repositioning splint was reported to increase the risk for posterior open bite, and for discs that are unstable or that have not returned to the original position (8). The mechanism of action, indications, or adverse effects for each type are not fully clarified, neither are the best materials and designs (7).

Another conservative treatment option is exercise therapy, which is used to improve strength, mobility, coordination, and to reduce pain in the joints and muscles (10). Previous reviews have already dwelt on the effectiveness of exercise therapy in the treatment of TMD (11-13). In this review, therapeutic exercise modalities are defined as follows: muscle-strengthening exercise, stretching exercise, jaw-opening exercise, postural exercise, and mobilization exercise $(10,12)$. Clinical and study-based outcomes have confirmed the effectiveness of therapeutic exercise modalities for the management of TMD due to improvements in local analgesia, muscle function, and restoration of local blood flow $(10,14)$. As techniques in which patients learn to relieve pain and stress through exercise therapy could help avoid the use of an occlusal splint in the long term, it is necessary to compare the efficacy of therapeutic exercise therapy with occlusal splint therapy $(12,13)$. To our knowledge, few data of reviews comparing the effectiveness of exercise therapy with occlusal splint therapy for the treatment of painful TMD have been reported (12,13). Armijo-Olivo et al. (12) conducted a systematic review and found no clear indication of superiority of exercise therapy versus other conservative treatments for TMD. A recent review concluded that the evidence level for prescribing exercises and occlusal splints in the treatment of painful TMD is low (13). Previous studies have provided inconclusive and controversial results; in addition, none of these systematic reviews provided a meta-analysis of the trials to investigate comparative effectiveness of exercise therapy and occlusal splint therapy for the treatment of painful TMD.

The purpose of this study was to compare the effectiveness of exercise therapy with occlusal splint therapy in relieving pain and improving mandibular movement for painful TMD treatment. Because patients are provided additional techniques to relieve pain and increase the mobility of the jaw through exercise therapy, we hypothesized that exercise therapy would be more effective than occlusal splint therapy for the management of those TMD symptoms.

We present the study in accordance with the PRISMA reporting checklist. Available at: http://dx.doi.org/10.21037/ apm-21-451.

\section{Methods}

\section{Data sources}

This meta-analysis was registered in PROSPERO (CRD42019138207), and was performed in accordance with the Preferred Reporting Items for Systematic Review and Meta-analyses (PRISMA) statement. PubMed d database root [1968] - March 1, 2020\}, Embase \{database root [1988] - March 1, 2020\}, and the Cochrane Central Register of Controlled Trials \{database root [1991] - March 1, 2020\} were independently searched by two of the researchers 
(LZ and DDW). Search terms were used according to a combination of medical subject headings ( $\mathrm{MeSH})$ terms, text words, and keywords as follows: [("temporomandibular joint disorders" [MeSH] OR "temporomandibular disorders" OR “craniomandibular disorders" [MeSH] OR "orofacial pain" OR "myofascial pain" OR "myofascial pain" OR "facial pain" [MeSH]) AND (exercise [MeSH] OR "physical therapy modalities" $[\mathrm{MeSH}]$ OR physiotherapy OR “exercise therapy") AND ("splints" [MeSH] OR "occlusal splints" [MeSH] OR "stabilization splint" OR "occlusal appliance" OR "occlusal splint therapy")], which were chosen based on previous reviews $(7,11)$. Only randomized control trials (RCTs) published in English were included in this meta-analysis. After a primary search, the reference lists of the relevant reviews and retrieved studies were also searched.

\section{Study selection}

The inclusion criteria for eligible articles were as follows.

\section{Participants}

This review restricted trials with participants meeting the following criteria: (I) diagnosis of TMD according to the RDC/TMD or any clinical diagnosis that involved symptoms and signs of TMD regardless of sex, or race (15); (II) adult (>18 years old); (III) muscle pain, TMJ pain, and/ or pain on movement of the mandible; (IV) musculoskeletal dysfunction; (V) no previous surgery in the TMJ, and (VI) no other serious comorbid conditions (e.g., neurological disease, rheumatologic disease, malignant disease).

\section{Studies and outcomes}

This review included RCTs that compared the effects of exercise therapy with occlusal splint therapy for the management of painful TMD. Studies that reported outcome measures of pain intensity and/or range of motion (ROM) were included. To truly investigate the therapeutic effects of exercise therapy and occlusal splint therapy, RCTs that compared occlusal splint therapy alone with therapeutic exercise were included. If there were two or more intervention groups (i.e., control/placebo groups) in a single study, only the occlusal splint therapy and exercise therapy group data were extracted for meta-analysis.

The exclusion criteria were as follows: (I) studies that were non-RCT, and non-peer reviewed articles, opinion articles, and papers not written in English; and (II) studies that included TMD caused by psychogenic, neurologic, or metabolic disorders.

\section{Data extraction and quality assessment}

Two independent reviewers (LZ and DDW) performed the search and evaluated every potentially relevant article according to the criteria listed above after an original screening of titles and abstracts. Original data collected from the full text of the eligible articles were compiled in predesigned forms that included objectives, participants, intervention protocol, outcome measures, and results. Discrepancies were resolved by analyzing the reasons for disagreement to achieve a consensus among reviewers at each stage.

A meta-epidemiological study conducted by Moseley et al. (16) concluded that researchers could use either the Cochrane Risk of Bias tool or the Physiotherapy Evidence Database (PEDro) scale to quantify risk of bias, but the instruments cannot be used interchangeably. As this metaanalysis focused on trials evaluating physical therapy interventions, PEDro scale was used to evaluate the blinding of participants and therapists in this review (16). The PEDro scale included 11 items and was applied to evaluate the risk of bias and completeness of statistical reporting (17). Because the first item assesses external validity and is not calculated in the PEDro score, the score ranges from 0 (poor quality) to 10 (high quality).

\section{Statistical analyses}

The mean differences and standard deviations of each study were calculated using data extracted from the full text of the included articles. Data in this review were analyzed using RevMan5.3 (Cochrane Collaboration). The standardized mean differences with $95 \%$ confidence intervals for continuous data were summarized with a random-effect model. Statistical heterogeneity was assessed using the chisquare based $\mathrm{Q}$ test at a significance of 0.1 . The $\mathrm{I}^{2}$ statistic quantified inconsistency across trials as unimportant (0-40\%), moderate (30-60\%), substantial (50-90\%), and considerable (75-100\%) (18). A P value of $<0.05$ was considered to indicate statistical significance.

\section{Patient and public involvement}

This study did not include patient or public involvement. 


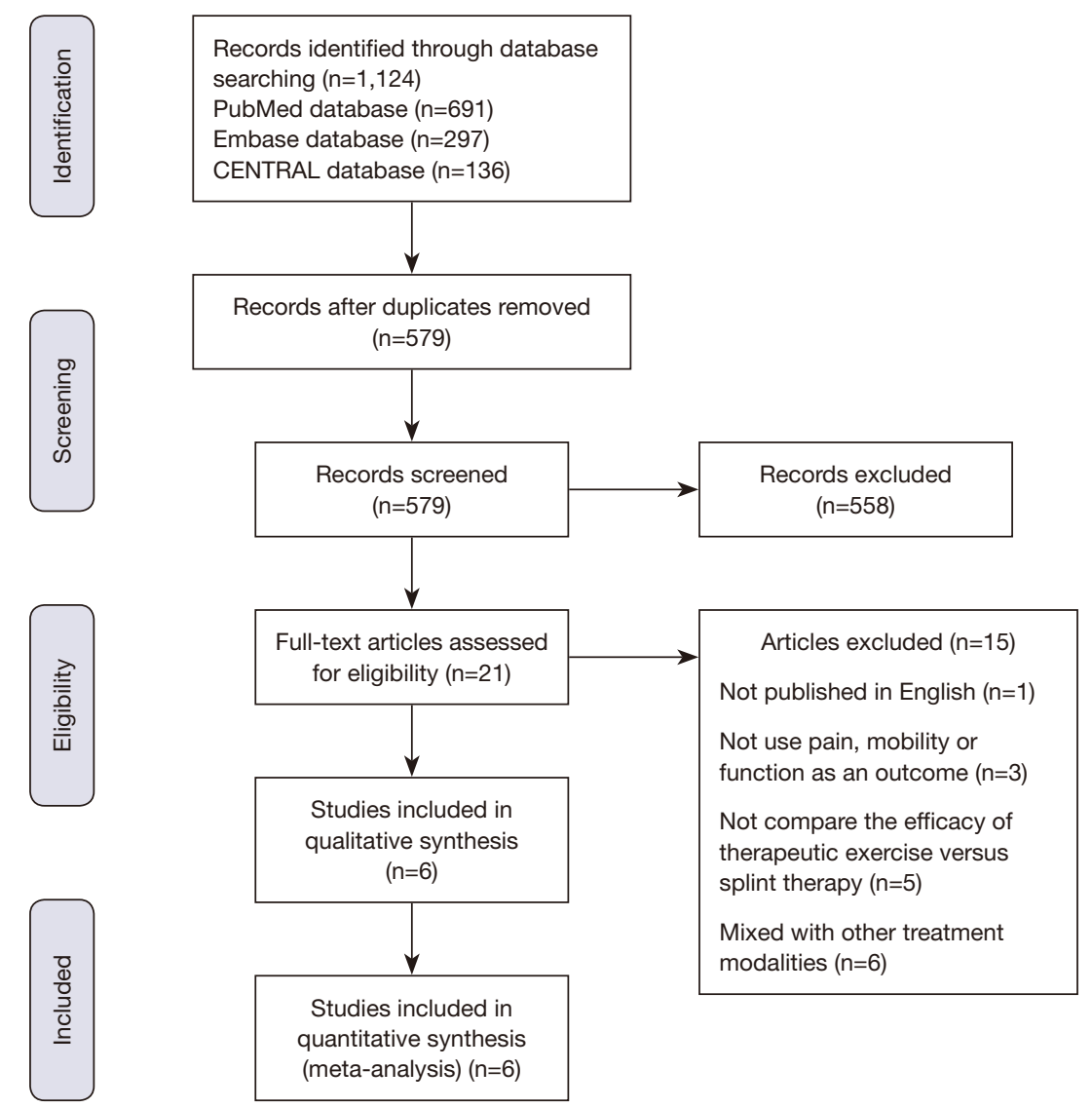

Figure 1 Flow chart of studies screening process based on the Preferred Reporting Items for Systematic Reviews and Meta-Analyses guideline.

\section{Results}

A total of 1,124 potentially relevant articles were identified. Of these, duplicated articles and articles which did not match the inclusion criteria were excluded after the initial screen of the titles and/or abstracts. Twenty-one articles that met the inclusion criteria were independently evaluated by the two reviewers. After screening the full text, 15 articles were excluded for the following reasons: published in Dutch, did not use pain and mandibular function as an outcome, did not compare the efficacy of therapeutic exercise and splint therapy, or included other treatment modalities. Finally, six RCTs met the inclusion criteria and were included in the meta-analysis (Figure 1) (19-24).

\section{Characteristics of the included studies}

Table 1 presents the details of the studies included in this review. A total of 498 participants were included, with 247 in the exercise therapy group and 251 in the occlusal splint therapy group. According to RDC/TMD criteria, five studies included patients with the diagnosis of myofascial pain (19,21-24), and the remaining study included patients with the diagnosis of myofascial pain $(97-100 \%)$ and/or arthralgia (55-61\%) (20). Exercise therapy was designed to restore normal musculoskeletal function and to reduce pain. In this review, exercise therapy programs were given by a physiotherapist and were divided into four categories: selfstretching exercise (20,22-24), jaw-opening exercises $(19,21)$, postural exercise $(20,22,23)$, and mobilization exercise $(19,21)$. All patients in the exercise therapy received exercise therapy interventions under the instruction and supervision of the physiotherapist. In five included studies, patients in the splint therapy group received the stabilization splint (19-23), and the remaining study used a resilient bite splint (24). All six studies reported a similar prescription of an occlusal splint given by a dentist in which the splint was used while 
Table 1 Data extracted from the included studies

\begin{tabular}{|c|c|c|c|c|c|c|}
\hline Author/country/year & Objective & Patient group & Interventions & Outcome measures & Result & PEDro \\
\hline $\begin{array}{l}\text { Haketa et al./ } \\
\text { Japan/2010 }\end{array}$ & $\begin{array}{l}\text { To evaluate the efficacy between two } \\
\text { treatment options for TMD: occlusal } \\
\text { splint and exercise }\end{array}$ & $\begin{array}{l}\text { The exercise therapy group } \\
\text { ( } \mathrm{n}=26) \text {; the splint therapy } \\
\text { group }(\mathrm{n}=26)\end{array}$ & $\begin{array}{l}\text { In the exercise group, participants performed self-mobilization } \\
\text { exercise and jaw-opening exercises by } 4 \text { sets per day. Participants in } \\
\text { the splint group wore a stabilization appliance while sleeping at night }\end{array}$ & $\begin{array}{l}\text { 1. Maximum mouth-opening range } \\
\text { 2. Maximum daily pain intensity } \\
\text { 3. Limitation of daily functions }\end{array}$ & $\begin{array}{l}\text { Therapeutic exercise brings earlier recovery of } \\
\text { jaw function compared with splints }\end{array}$ & 8 \\
\hline $\begin{array}{l}\text { Alejandro et al./ } \\
\text { USA/2012 }\end{array}$ & $\begin{array}{l}\text { To evaluate treatment outcome of a } \\
\text { jaw exercise regimen in comparison } \\
\text { to that of the stabilization splint of } \\
\text { TMD }\end{array}$ & $\begin{array}{l}\text { The exercise therapy group } \\
\text { ( } \mathrm{n}=28) ; \text { the splint therapy } \\
\text { group }(\mathrm{n}=64)\end{array}$ & $\begin{array}{l}\text { Subjects in the jaw exercise group were instructed to open their jaw } \\
\text { as far as possible without pain and hold the jaw in that position for } \\
\text { five seconds, and then close their jaw and rest } 10 \text { seconds. Subjects } \\
\text { assigned to the stabilization splint group were instructed to wear } \\
\text { their splints every night }\end{array}$ & $\begin{array}{l}\text { 1. The Craniomandibular Index (CMI): severity of TMD signs and } \\
\text { symptoms } \\
\text { 2. Pain: VAS } \\
\text { 3. The modified Symptom Severity Index Questionnaire }\end{array}$ & $\begin{array}{l}\text { The jaw exercise was not found to be statistically } \\
\text { significantly inferior to the stabilization splint }\end{array}$ & 7 \\
\hline $\begin{array}{l}\text { Katyayan et al./ } \\
\text { India/2014 }\end{array}$ & $\begin{array}{l}\text { lo assess the efficacy of stabilization } \\
\text { splint therapy and masticatory } \\
\text { muscle exercises on TMD related } \\
\text { facial pain and mandibular mobility }\end{array}$ & $\begin{array}{l}\text { The masticatory muscle } \\
\text { exercise group }(n=40) \text {; the } \\
\text { splint therapy group }(n=40)\end{array}$ & $\begin{array}{l}\text { Patients were instructed to perform a standardized program for } \\
\text { masticatory muscle exercises, including jaw-opening exercise, } \\
\text { resistance exercise, and self-mobilization. The patients were } \\
\text { instructed to wear the stabilization appliance while sleeping at night } \\
\text { for a minimum of } 12 \mathrm{~h}\end{array}$ & $\begin{array}{l}\text { 1. The ranges of movements of the mandible } \\
\text { 2. Deviations of movements } \\
\text { 3. TMJ sounds } \\
\text { 4. Masticatory muscle pain } \\
\text { 5. TMJ pain }\end{array}$ & $\begin{array}{l}\text { Stabilization splint treatment has no better } \\
\text { results in relieving facial pain and increasing } \\
\text { the mobility of the mandible than masticatory } \\
\text { muscle exercises alone over a } 6 \text {-months' time } \\
\text { interval }\end{array}$ & 8 \\
\hline $\begin{array}{l}\text { Van Grootel et al./ } \\
\text { Netherlands/2017 }\end{array}$ & $\begin{array}{l}\text { To evaluate treatment outcome of } \\
\text { exercise therapy in comparison to } \\
\text { that of splint therapy of myogenous } \\
\text { TMD }\end{array}$ & $\begin{array}{l}\text { The exercise therapy group } \\
(\mathrm{n}=37) \text {; the splint therapy } \\
\text { group }(\mathrm{n}=35)\end{array}$ & $\begin{array}{l}\text { Postural exercise and self-stretching of jaw-closing muscles were } \\
\text { performed to avoid stress related pain from the masticatory system. } \\
\text { The splint was used as much as possible, at least in the evening and } \\
\text { overnight for a minimum of } 10 \text { to } 12 \mathrm{~h}\end{array}$ & $\begin{array}{l}\text { 1. Treatment duration } \\
\text { 2. Success rate } \\
\text { 3. Number of visits } \\
\text { 4. VAS }\end{array}$ & $\begin{array}{l}\text { Exercise therapy may be preferred as initial } \\
\text { therapy over occlusal splint therapy in stepped- } \\
\text { care of myogenous TMD }\end{array}$ & 6 \\
\hline $\begin{array}{l}\text { Tamer et al./ } \\
\text { Egypt/2018 }\end{array}$ & $\begin{array}{l}\text { To compare the effects of a short- } \\
\text { term exercise treatment versus } \\
\text { occlusive splinting on pain and ROM } \\
\text { in TMD patients }\end{array}$ & $\begin{array}{l}\text { Exercise group ( } n=56) ; \\
\text { occlusive splinting group } \\
(n=56)\end{array}$ & $\begin{array}{l}\text { Exercise treatment included postural exercise and self-stretching for } \\
15 \text { min per session, } 2 \text { weekly for } 6 \text { weeks. Splinting was used daily } \\
\text { for a period of } 6 \text { weeks }\end{array}$ & $\begin{array}{l}\text { 1. Pain: VAS } \\
\text { 2. ROM: TMJ opening index (TOI) }\end{array}$ & $\begin{array}{l}\text { Therapeutic exercise could be a better initial } \\
\text { treatment than occlusive splint in relieving pain } \\
\text { and improving ROM in cases of myogenic } \\
\text { temporomandibular dysfunction }\end{array}$ & 7 \\
\hline $\begin{array}{l}\text { Wänman et al.// } \\
\text { Sweden/2020 }\end{array}$ & $\begin{array}{l}\text { To evaluate the effect of exercise and } \\
\text { bite splint therapy, respectively, in } \\
\text { patients with TMD }\end{array}$ & $\begin{array}{l}\text { The exercise group }(n=60) \text {; } \\
\text { bite splint group }(n=30)\end{array}$ & $\begin{array}{l}\text { Patients in exercise therapy group were instructed to do two } \\
\text { different trainings: jaw closing and opening movement and isometric } \\
\text { exercises. Patients in the splint therapy group received a resilient bite } \\
\text { splint that should be used during sleeping }\end{array}$ & $\begin{array}{l}\text { 1. The frequency of TMJ clicking sounds, TMJ locking } \\
\text { 2. Jaw pain } \\
\text { 3. Jaw function limitation scale-20 } \\
\text { 4. The Patient Global Impression of Change (PGIC) }\end{array}$ & $\begin{array}{l}\text { Jaw exercise programmes and bite splint } \\
\text { therapy had similar positive effects on perceived } \\
\text { severity of TMJ clicking sounds }\end{array}$ & 9 \\
\hline
\end{tabular}

TMD, temporomandibular disorders; TMJ, temporomandibular joint; RCT, randomized controlled trial; ROM, range of motion; VAS, visual analogue scale; PEDro, Physiotherapy Evidence Database. 


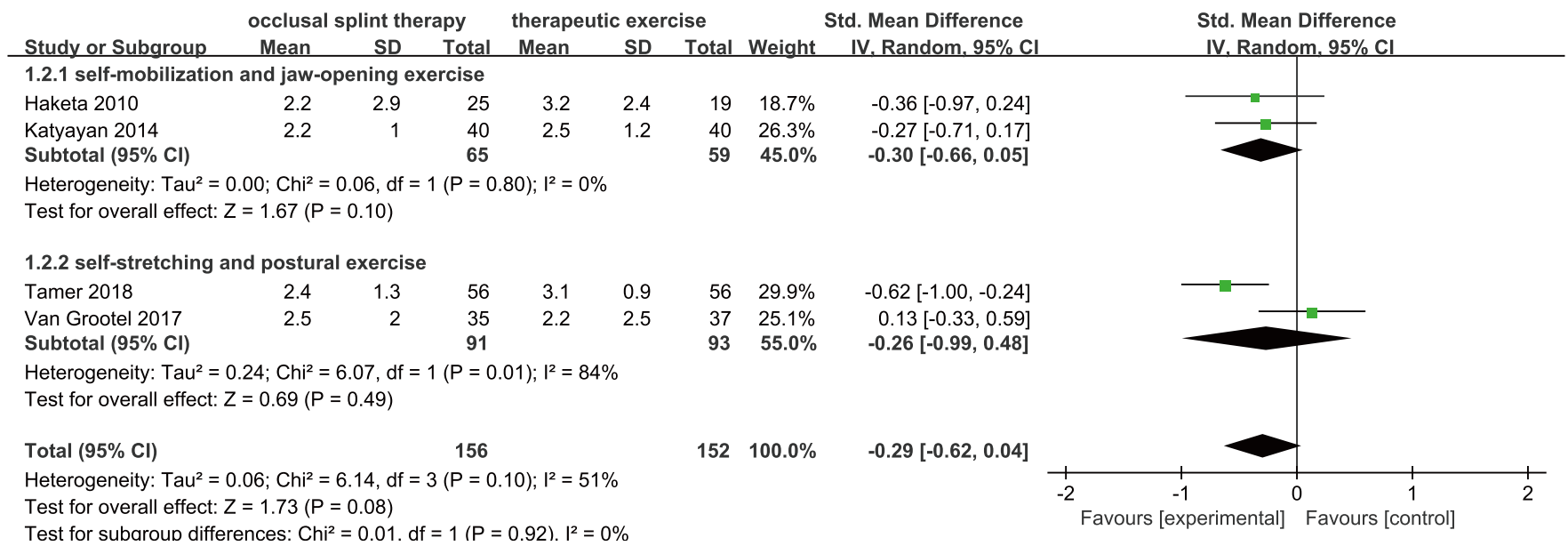

Figure 2 Forest plot of comparison: occlusal splint therapy vs. exercise therapy, outcome: pain relief.

sleeping at night. Recommendations for the duration of wearing the splint varied, with four studies that required patients to wear the splint as much as possible $(19,21,22,24)$. and the other two studies required patients to wear the splint for 4-6 weeks $(20,23)$. All included studies reported similarities in the baseline comparisons of TMD symptoms between exercise therapy group and occlusal splint therapy group.

\section{Outcome measures}

Five studies reported measurements of pain intensity, and the intensity of the present facial pain was measured with the Visual Analog Scale (VAS) (19-23). Three studies reported the performance of a clinical examination focusing on the ranges of movement of the mandible and deviations of movements $(19,21,24)$. In addition to the measurement of maximum mouth-opening range, Katyayan et al. (21) and Wänman et al. (24) also reported the measurement of right lateral excursion, left lateral excursion, and protrusion.

\section{Methodologic quality}

The methodologic quality of the included RCTs varied. Assessment with the PEDro scale (Table 1) revealed that five of the six included studies were shown to have strong methodologic quality (scores higher than 6).

\section{Effects on pain relief}

Figure 2 showed the standardized mean differences between the occlusal splint therapy and exercise therapy groups regarding the effects on pain. Pain intensity was reported in two studies of subgroup 1 using self-mobilization exercise and jaw-opening exercise showing unimportant heterogeneity $\left(\mathrm{I}^{2}=0 \% ; \mathrm{P}=0.80\right)$, and two other RCTs of subgroup 2 using self-stretching exercise and postural exercise showed substantial heterogeneity $\left(\mathrm{I}^{2}=84 \% ; \mathrm{P}=0.01\right)$. Additionally, overall heterogeneity for this outcome was moderate $\left(\mathrm{I}^{2}=51 \% ; \mathrm{P}=0.10\right)$, with unimportant heterogeneity observed among subgroups $\left(\mathrm{I}^{2}=0 \% ; \mathrm{P}=0.92\right)$. The findings suggested that there were no significant differences in pain relief between occlusal splint therapy and physiotherapy $(\mathrm{P}=0.08$; weighted standardized mean difference $-0.29 ; 95 \%$ CI, -0.62 to 0.04 ).

\section{Effects on maximum mouth-opening range}

Figure 3 demonstrated the standardized mean differences between the occlusal splint therapy and exercise therapy groups regarding the effects on maximum mouth-opening range. Subgroup 1 using the stabilization splint showed substantial heterogeneity $\left(\mathrm{I}^{2}=69 \% ; \mathrm{P}=0.07\right)$, and one RCT of subgroup 2 using the resilient bite splint reported this outcome. Additionally, overall heterogeneity for this outcome was moderate $\left(\mathrm{I}^{2}=40 \% ; \mathrm{P}=0.19\right)$, with unimportant heterogeneity observed among subgroups $\left(\mathrm{I}^{2}=0 \% ; \mathrm{P}=0.72\right)$. The findings suggested that there were no significant differences for maximum mouth-opening range between occlusal splint therapy and exercise therapy $(\mathrm{P}=0.51$; weighted standardized mean difference $0.12 ; 95 \% \mathrm{CI},-0.24$ to 0.48$)$. 


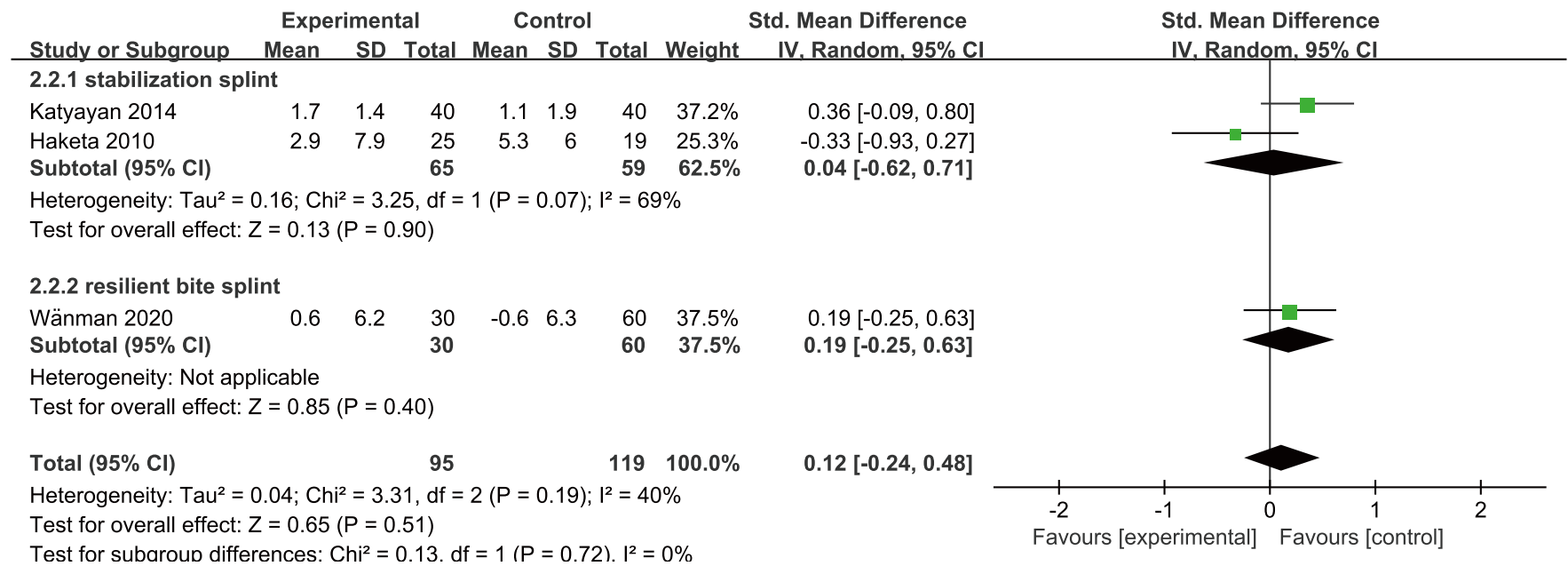

Figure 3 Forest plot of comparison: occlusal splint therapy $v$ s. exercise therapy, outcome: maximum mouth-opening range.

\section{Effects on laterotrusion and protrusion}

Figure 4 shows the standardized mean differences between the occlusal splint therapy and exercise therapy groups regarding the effects on laterotrusion and protrusion. The findings suggested that there was a non-significant difference for right laterotrusion $(\mathrm{P}=0.99$; weighted standardized mean difference $-0.00 ; 95 \% \mathrm{CI},-0.31$ to 0.31 , $\left.\mathrm{I}^{2}=0 \%\right)$, left laterotrusion $(\mathrm{P}=0.32$; weighted standardized mean difference $0.16 ; 95 \% \mathrm{CI},-0.16$ to $0.48 ; \mathrm{I}^{2}=4 \%$ ), and protrusion $(\mathrm{P}=0.77$; weighted standardized mean difference $0.06 ; 95 \% \mathrm{CI},-0.32$ to $\left.0.43 ; \mathrm{I}^{2}=31 \%\right)$.

\section{Discussion}

Conservative measures are recommended as initial therapy for painful TMD. The evaluation of TMD symptoms such as pain and mandibular movement is essential for the management of TMD patients, as pain is one of the clinical symptoms of TMD, and one of main reasons for patients seeking treatment and assistance. In this review, the hypothesis was not met, there was no significant difference in pain relief and mandibular ROM improvement between exercise therapy and occlusal splint therapy for patients with painful TMD.

Treatment strategies for exercise therapy and occlusal splint therapy are founded on non-invasive, reversible interventions (13). List et al. (25) concluded that conservative treatment including exercise therapy and occlusal splint therapy could effectively relieve TMD pain and increase jaw opening. Previously, the efficacy of exercise therapy versus occlusal splint therapy for TMD has been controversial $(12,13)$. Some authors suggested that therapeutic exercises under supervision of the physiotherapist had an additional effect on patient's well-being and thus might help to encourage patient's coping strategies, which may be associated with the superiority of exercise therapy over occlusal splint therapy $(10,11)$. Although in this review, patients in the exercise therapy group received exercises under supervision of the physiotherapist, the results of the present review are in accordance with other studies; no significant difference was found for pain relief between exercise therapy and occlusal splint therapy $(12,13)$. One possible explanation for this disconcordance could be the difference of included participants in the studies. The present review included patients with myofascial pain and/ or arthralgia. It has been found that patients with pain in the TMJ, the masticatory muscles region receive less benefit from exercise therapy compared with patients with mandibular dysfunction (19). Differences in the treatment outcome could be due to the heterogeneity of the patient psychological and material factors (26), however, this possible heterogeneity could not be taken account into this review. Sample sizes vary across studies, which may also explain why some studies have shown the superiority of exercise therapy compared with occlusal splint therapy. Due to these diverse opinions, further RCTs to identify comparative effectiveness of exercise therapy and occlusal splint therapy are obviously required. The finding of the present meta-analysis demonstrated that no significant 


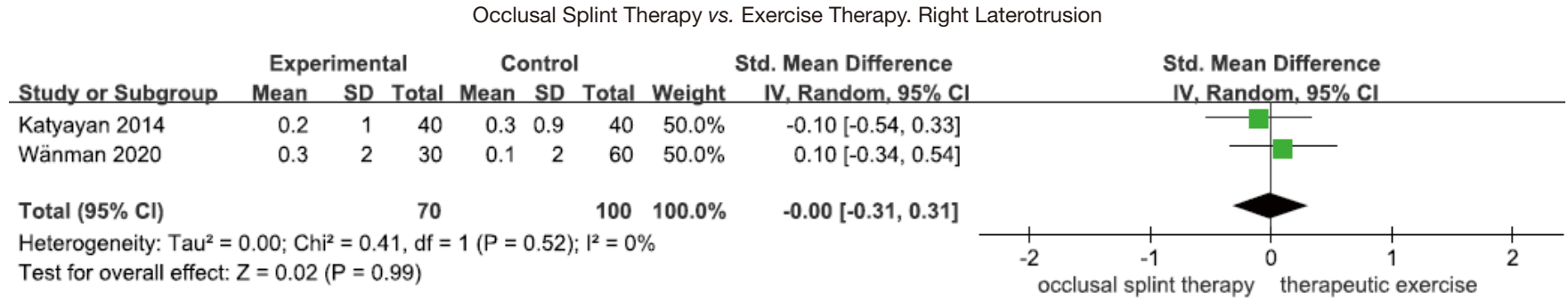

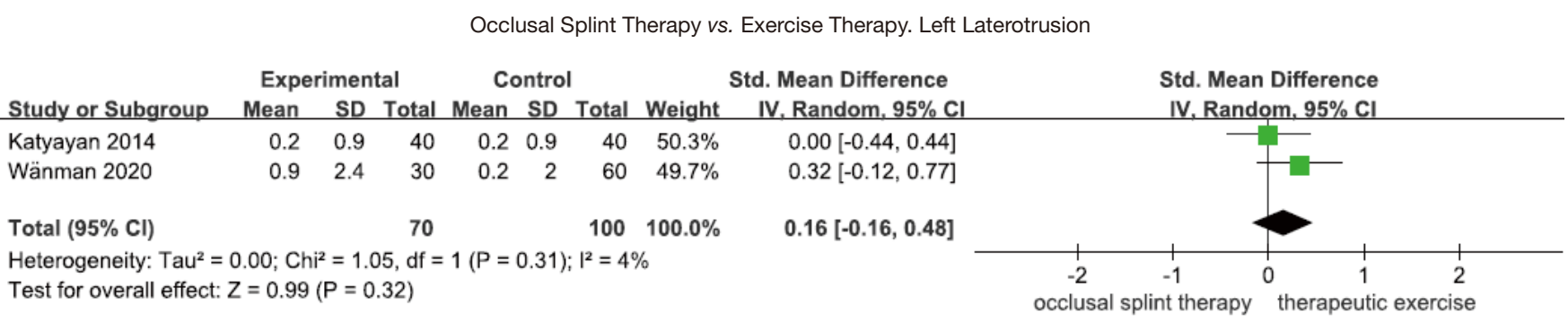

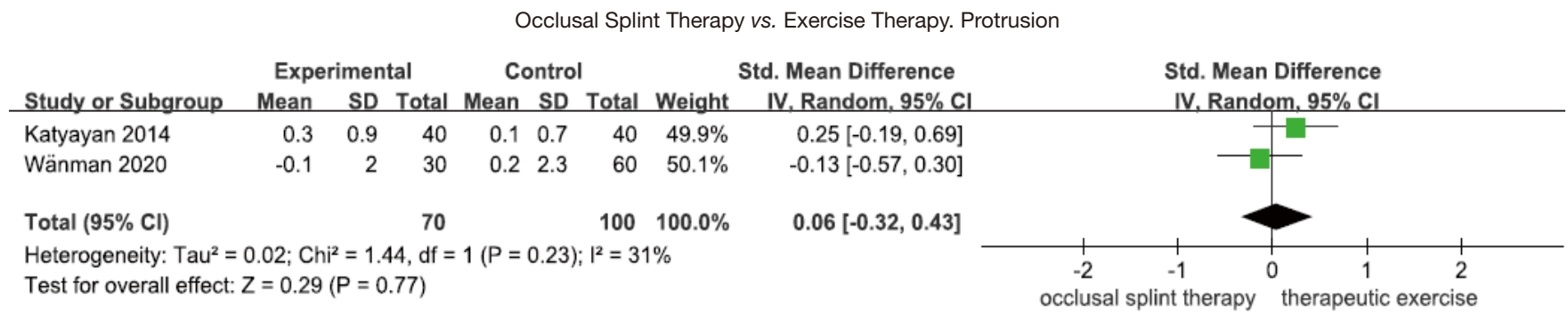

Figure 4 Forest plot of comparison: occlusal splint therapy vs. exercise therapy, outcome: laterotrusion and protrusion.

difference was found for mandibular movement between the two treatment modalities. Our results are in line with previous studies on TMD patients that concluded that exercise therapy and occlusal splint therapy had similar positive effects on the improvement of mandibular ROM $(4,12)$. Given the small number of studies included in the sub-analysis for pain relief and mobility improvement, and the small overall standardized mean difference observed, these results have to be interpreted with caution. There was a high risk of bias in 3 of the studies with no blinding of participants $(17,19,20)$. Many patients across the studies were lost to follow-up $(19,21,22)$. Findings of the present study are not generalizable, and further meta-analyses and studies are needed before adopting these findings in clinical practice.

Therapeutic exercise has an activating approach with the aim to reduce sensory features and muscle tension around the jaw, and to mobilize and challenge dysfunction and pain
$(12,27)$. Various mechanisms by which exercise therapy improves TMD symptoms have been explored $(28,29)$. Patients with painful TMD exhibited reduced blood flow to the masseter muscles, mainly caused by vasoconstriction that resulted from hyperactivity of the muscles (28). Consequently, the transport of metabolites and nutrients was impeded, which could cause the accumulation of by-products, thereby triggering pain (29). Mobilization was applied to stimulate parasympathetic activity, which could increase local blood flow, and lead to an analgesic effect based on the activation of a pain-gate mechanism (30). Stretching of the jaw muscles could lead to a reduction in the symptoms of TMD as well as an improvement in mandibular function (13). In addition, the neuromuscular, vascular, and rehabilitationary benefits of jaw exercise and posture correction exercise for TMD patients have been reported in previous studies $(31,32)$. The positive effect of relieving pain and improving mandibular mobility may thus be assigned to the exercise therapy for patients with 
painful TMD.

The use of occlusal splints for patients with TMD is common in dentistry $(7,8)$. The comprehensive treatment effect of occlusal splints on TMD has been reported to be $70-75 \%$ (5). The occlusal splint has a fundamental intention to alter the biomechanical loading on the TMJ and to decrease parafunctional activity (7). An occlusal splint could change the position of the TMJ by increasing the vertical dimension of the mouth (8). Furthermore, occlusal splint therapy affected motor control by changing the activity patterns of the jaw-closing muscles (33). The reduction in the electrical activity of the masticatory muscles might explain the mechanism for the therapeutic effects of occlusal splint therapy (34). Some researchers suggested that only immediate reductions in electromyographic activity are achieved after occlusal splint therapy; however, after long-term use of occlusal splints, no reductions occur due to the adaptive mechanisms of the muscles $(34,35)$. Alajbeg et al. (36) reported that stabilization splints resulted in a significant decrease in pain intensity compared with other devices. Considering disc displacements, anterior repositioning splints were able to return discs to their original position for those with anterior disc displacement with reduction, but they were not applicable for those with anterior disc displacement without reduction (8). However, there is no high-quality evidence to determine the mechanism of occlusal splints and to make decisions regarding the indications for each type. According to the findings of this review, occlusal splints have been recommended to use during sleep in TMD patients, but there is still controversy about the duration of wearing the splint.

Some limitations of this review should be addressed. First, given the difference in subtype included in the RDC/ TMD diagnostic criteria, treating all patients with TMD as if they would respond the same to any intervention is not ideal. Second, only six studies with 498 patients were included in this analysis. Third, other data sources such as SCI-E or Scopus which could have increased the number and quality of the retrieved RCTs were not considered in this review. The findings were not definitive and generalizable due to the small number of included studies, and should be interpreted with caution. Further study is necessary before adopting these findings in clinical practice.

\section{Conclusions}

The effectiveness of occlusal splint therapy and exercise therapy was equivalent in pain relief and improvement of mandibular movement for painful TMD patients; exercises did not show clear superiority over occlusal splints for treating painful TMD. Given the limitations of the study, no high-quality evidence was found, indicating that there is great uncertainty about the effectiveness of exercise therapy versus occlusal splint therapy for TMD. It appears that high-quality, large-scale, and well-designed RCTs that determine the diagnostic criteria for TMD and isolate the type of exercise and occlusal splint are needed to compare the effects of exercise therapy and occlusal splint therapy for the management of TMD.

\section{Acknowledgments}

This manuscript has been edited for English language by professional editors at Editage, a division of Cactus Communications.

Funding: This work is supported by the Clinical Research Program (Grant No. JYLJ201901) and the Shanghai Municipal Science and Technology Major Project (Grant No. 19441908400).

\section{Footnote}

Reporting Checklist: The authors have completed the PRISMA reporting checklist. Available at http://dx.doi. org/10.21037/apm-21-451

Peer Review File: Available at http://dx.doi.org/10.21037/ apm-21-451

Conflicts of Interest: All authors have completed the ICMJE uniform disclosure form (available at: http://dx.doi. org/10.21037/apm-21-451). The authors have no conflicts of interest to declare.

Ethical Statement: The authors are accountable for all aspects of the work in ensuring that questions related to the accuracy or integrity of any part of the work are appropriately investigated and resolved.

Open Access Statement: This is an Open Access article distributed in accordance with the Creative Commons Attribution-NonCommercial-NoDerivs 4.0 International License (CC BY-NC-ND 4.0), which permits the noncommercial replication and distribution of the article with the strict proviso that no changes or edits are made and the 
original work is properly cited (including links to both the formal publication through the relevant DOI and the license). See: https://creativecommons.org/licenses/by-nc-nd/4.0/.

\section{References}

1. Garrigós-Pedrón M, Elizagaray-García I, DomínguezGordillo AA, et al. Temporomandibular disorders: improving outcomes using a multidisciplinary approach. J Multidiscip Healthc 2019;12:733-47.

2. Wieckiewicz M, Boening K, Wiland P, et al. Reported concepts for the treatment modalities and pain management of temporomandibular disorders. J Headache Pain 2015;16:106.

3. Alrashdan MS, Alkhader M. Psychological factors in oral mucosal and orofacial pain conditions. Eur J Dent 2017;11:548-52.

4. Melo RA, de Resende CMBM, Rêgo CRF, et al. Conservative therapies to treat pain and anxiety associated with temporomandibular disorders: a randomized clinical trial. Int Dent J 2020;70:245-53.

5. Kuzmanovic Pficer J, Dodic S, Lazic V, et al. Occlusal stabilization splint for patients with temporomandibular disorders: Meta-analysis of short and long term effects. PLoS One 2017;12:e0171296.

6. Wahlund K, List T, Larsson B. Treatment of temporomandibular disorders among adolescents: a comparison between occlusal appliance, relaxation training, and brief information. Acta Odontol Scand 2003;61:203-11.

7. Zhang C, Wu J, Deng D, et al. Efficacy of splint therapy for the management of temporomandibular disorders: a meta-analysis. Oncotarget 2016;7:84043-53.

8. Greene CS, Menchel HF. The Use of Oral Appliances in the Management of Temporomandibular Disorders. Oral Maxillofac Surg Clin North Am 2018;30:265-77.

9. Al-Ani MZ, Davies SJ, Gray RJ, et al. Stabilisation splint therapy for temporomandibular pain dysfunction syndrome. Cochrane Database Syst Rev 2004;(1):CD002778.

10. Rashid A, Matthews NS, Cowgill H. Physiotherapy in the management of disorders of the temporomandibular joint-perceived effectiveness and access to services: a national United Kingdom survey. Br J Oral Maxillofac Surg 2013;51:52-7.

11. La Touche R, Boo-Mallo T, Zarzosa-Rodríguez J, et al. Manual therapy and exercise in temporomandibular joint disc displacement without reduction. A systematic review. Cranio 2020. [Epub ahead of print]. doi:
10.1080/08869634.2020.1776529.

12. Armijo-Olivo S, Pitance L, Singh V, et al. Effectiveness of Manual Therapy and Therapeutic Exercise for Temporomandibular Disorders: Systematic Review and Meta-Analysis. Phys Ther 2016;96:9-25.

13. Eliassen M, Hjortsjö C, Olsen-Bergem H, et al. Selfexercise programmes and occlusal splints in the treatment of TMD-related myalgia-Evidence-based medicine? J Oral Rehabil 2019;46:1088-94.

14. Dostalová T, Hlinakova P, Kasparova M, et al. Effectiveness of physiotherapy and GaAlAs laser in the management of temporomandibular joint disorders. Photomed Laser Surg 2012;30:275-80.

15. Schiffman E, Ohrbach R, Truelove E, et al. Diagnostic Criteria for Temporomandibular Disorders (DC/TMD) for Clinical and Research Applications: recommendations of the International RDC/TMD Consortium Network* and Orofacial Pain Special Interest Group†. J Oral Facial Pain Headache 2014;28:6-27.

16. Moseley AM, Rahman P, Wells GA, et al. Agreement between the Cochrane risk of bias tool and Physiotherapy Evidence Database (PEDro) scale: A meta-epidemiological study of randomized controlled trials of physical therapy interventions. PLoS One 2019;14:e0222770.

17. de Morton NA. The PEDro scale is a valid measure of the methodological quality of clinical trials: a demographic study. Aust J Physiother 2009;55:129-33.

18. Jørgensen L, Paludan-Müller AS, Laursen DR, et al. Evaluation of the Cochrane tool for assessing risk of bias in randomized clinical trials: overview of published comments and analysis of user practice in Cochrane and non-Cochrane reviews. Syst Rev 2016;5:80.

19. Haketa T, Kino K, Sugisaki M, et al. Randomized clinical trial of treatment for TMJ disc displacement. J Dent Res 2010;89:1259-63.

20. Tavera AT, Montoya MC, Calderón EF, et al. Approaching temporomandibular disorders from a new direction: a randomized controlled clinical trial of the TMDes ear system. Cranio 2012;30:172-82.

21. Katyayan PA, Katyayan MK, Shah RJ, et al. Efficacy of appliance therapy on temporomandibular disorder related facial pain and mandibular mobility: a randomized controlled study. J Indian Prosthodont Soc 2014;14:251-61.

22. van Grootel RJ, Buchner R, Wismeijer D, et al. Towards an optimal therapy strategy for myogenous TMD, physiotherapy compared with occlusal splint therapy in an RCT with therapy-and-patient-specific treatment durations. BMC Musculoskelet Disord 2017;18:76. 
23. Shousha TM, Soliman ES, Behiry MA. The effect of a short term conservative physiotherapy versus occlusive splinting on pain and range of motion in cases of myogenic temporomandibular joint dysfunction: a randomized controlled trial. J Phys Ther Sci 2018;30:1156-60.

24. Wänman A, Marklund S. Treatment outcome of supervised exercise, home exercise and bite splint therapy, respectively, in patients with symptomatic disc displacement with reduction: A randomised clinical trial. J Oral Rehabil 2020;47:143-9.

25. List T, Axelsson S. Management of TMD: evidence from systematic reviews and meta-analyses. J Oral Rehabil 2010;37:430-51.

26. Conti PC, de Azevedo LR, de Souza NV, et al. Pain measurement in TMD patients: evaluation of precision and sensitivity of different scales. J Oral Rehabil 2001;28:534-9.

27. Zhang Y, Montoya L, Ebrahim S, et al. Hypnosis/Relaxation therapy for temporomandibular disorders: a systematic review and meta-analysis of randomized controlled trials. J Oral Facial Pain Headache 2015;29:115-25.

28. Häggman-Henrikson B, Wiesinger B, Wänman A. The effect of supervised exercise on localized TMD pain and TMD pain associated with generalized pain. Acta Odontol Scand 2018;76:6-12.

29. Amat P. Managing temporomandibular disorders (TMD) by integrating exercise therapy into therapeutic patient educational programs: why, when, how? J Dentofacial Anom Orthod 2011;14:206.

30. Amaral AP, Politti F, Hage YE, et al. Immediate effect of nonspecific mandibular mobilization on postural control in subjects with temporomandibular disorder: a single-blind,

Cite this article as: Zhang L, Xu L, Wu D, Yu C, Fan S, Cai B. Effectiveness of exercise therapy versus occlusal splint therapy for the treatment of painful temporomandibular disorders: a systematic review and meta-analysis. Ann Palliat Med 2021;10(6):6122-6132. doi: 10.21037/apm-21-451 randomized, controlled clinical trial. Braz J Phys Ther 2013;17:121-7.

31. Chaves TC, Turci AM, Pinheiro CF, et al. Static body postural misalignment in individuals with temporomandibular disorders: a systematic review. Braz J Phys Ther 2014;18:481-501.

32. Storm Mienna C, Glas L, Magnusson M, et al. Patients' experiences of supervised jaw-neck exercise among patients with localized TMD pain or TMD pain associated with generalized pain. Acta Odontol Scand 2019;77:495-501.

33. Chandu A, Suvinen TI, Reade PC, et al. The effect of an interocclusal appliance on bite force and masseter electromyography in asymptomatic subjects and patients with temporomandibular pain and dysfunction. J Oral Rehabil 2004;31:530-7.

34. Gomes CA, El Hage Y, Amaral AP, et al. Effects of massage therapy and occlusal splint therapy on electromyographic activity and the intensity of signs and symptoms in individuals with temporomandibular disorder and sleep bruxism: a randomized clinical trial. Chiropr Man Therap 2014;22:43.

35. Dahlström L, Carlsson GE, Carlsson SG. Comparison of effects of electromyographic biofeedback and occlusal splint therapy on mandibular dysfunction. Scand J Dent Res 1982;90:151-6.

36. Alajbeg IZ, Gikić M, Valentić-Peruzović M. Changes in pain intensity and oral health-related quality of life in patients with temporomandibular disorders during stabilization splint therapy--a pilot study. Acta Clin Croat 2014;53:7-16. 